OPEN ACCESS

Edited by:

David John Oliver

University of Kent, United Kingdom

Reviewed by:

Ambereen Mehta

Johns Hopkins Bayview Medical

Center, United States

Nuno Tavares,

University of Portsmouth,

United Kingdom

*Correspondence:

Wendy S. Johnston

wendyj@ualberta.ca

Specialty section:

This article was submitted to Neurocritical and Neurohospitalist

Care,

a section of the journal

Frontiers in Neurology

Received: 20 March 2021

Accepted: 09 July 2021

Published: 04 August 2021

Citation:

Genuis SK, Luth W, Campbell S,

Bubela T and Johnston WS (2021)

Communication About End of Life for

Patients Living With Amyotrophic Lateral Sclerosis: A Scoping Review of the Empirical Evidence.

Front. Neurol. 12:683197. doi: 10.3389/fneur.2021.683197

\section{Communication About End of Life for Patients Living With Amyotrophic Lateral Sclerosis: A Scoping Review of the Empirical Evidence}

\author{
Shelagh K. Genuis ${ }^{1}$, Westerly Luth ${ }^{2}$, Sandra Campbell ${ }^{3}$, Tania Bubela ${ }^{4}$ and \\ Wendy S. Johnston ${ }^{\text {* }}$ \\ 'Division of Neurology, Department of Medicine, University of Alberta, Edmonton, AB, Canada, ${ }^{2}$ School of Public Health, \\ University of Alberta, Edmonton, AB, Canada, ${ }^{3} \mathrm{~J}$ ohn W. Scott Health Sciences Library, Faculty of Medicine and Dentistry, \\ University of Alberta, Edmonton, AB, Canada, ${ }^{4}$ Faculty of Health Sciences, Simon Fraser University, Burnaby, BC, Canada
}

Background: Communication about end of life, including advance care planning, lifesustaining therapies, palliative care, and end-of-life options, is critical for the clinical management of amyotrophic lateral sclerosis patients. The empirical evidence base for this communication has not been systematically examined.

Objective: To support evidence-based communication guidance by (1) analyzing the scope and nature of research on health communication about end of life for amyotrophic lateral sclerosis; and (2) summarizing resultant recommendations.

Methods: A scoping review of empirical literature was conducted following recommended practices. Fifteen health-related and three legal databases were searched; 296 articles were screened for inclusion/exclusion criteria; and quantitative data extraction and analysis was conducted on 211 articles with qualitative analysis on a subset of 110 articles that focused primarily on health communication. Analyses summarized article characteristics, themes, and recommendations.

Results: Analysis indicated a multidisciplinary but limited evidence base. Most reviewed articles addressed end-of-life communication as a peripheral focus of investigation. Generic communication skills are important; however, substantive and sufficient diseaserelated information, including symptom management and assistive devices, is critical to discussions about end of life. Few articles discussed communication about specific endof-life options. Communication recommendations in analyzed articles draw attention to communication processes, style and content but lack the systematized guidance needed for clinical practice.

Conclusions: This review of primary research articles highlights the limited evidencebase and consequent need for systematic, empirical investigation to inform effective communication about end of life for those with amyotrophic lateral sclerosis. This will provide a foundation for actionable, evidence-based communication guidelines about end of life. Implications for research, policy, and practice are discussed.

Keywords: advance care planning, amyotrophic lateral sclerosis, health communication, palliative care, terminal care, review 


\section{INTRODUCTION}

Communication about advance care planning, life-sustaining therapies, palliative care and other options in the last months of life is central to the clinical management of fatal neurological diseases, such as amyotrophic lateral sclerosis (ALS) (1-5). ALS is a degenerative motor neuron disease characterized by progressive motor impairment leading to severe disability and eventual respiratory failure (6). ALS incidence is between 0.6 and 3.8 per 100,000 person-years and its prevalence is $4.1-8.4$ per 100,000 persons (7); it is considered a "rare disease" (8). Patients living with ALS confront significant practical and existential losses $(9-12)$ as they contend with an uncertain and variable disease trajectory, a median overall survival of 30 months after symptom onset, and a $5-10 \%$ survival rate one decade after diagnosis $(13,14)$. Accordingly, there is a need for clear and frequent communication with patients and their families over the course of the disease (15).

Timely and ongoing discussion about end of life (including advance care planning, technology for symptom management, palliative care, and other end of life options) is particularly important for ALS patients. Therapies introduced for symptom management, such as non-invasive ventilation, may rapidly become life-sustaining, thus changing the natural disease trajectory and making it difficult to predict when a patient is entering the last months of life $(16,17)$. Further, many patients experience substantial functional communication and cognitive difficulties, which may interfere with communication at later stages of the disease (6). Effective discussions about end of life help alleviate anticipatory fears, especially around choking (6); guide decisions about life-sustaining therapies (18-20); facilitate decisions that are consistent with patients' and families' priorities and needs over time $(6,21,22)$; and preserve patient autonomy and dignity (23).

Compounding a complex communication environment and in the ongoing absence of a cure or treatment, ALS is perceived by patients and their families as a "death sentence" (24), "the self under attack" or a "downward journey" (25). This is in contrast to the empowering representation of "fighting" diseases with multiple treatment options, such as many cancers $(26,27)$. Moreover, increasing discussion and legalization of voluntary assisted death across jurisdictions, including both physicianassisted suicide and euthanasia (28-30), and a focus on ALS in court cases, case studies published in medical journals, and media portrayals of voluntary assisted death (31-35) raises the possibility that this option may become the focus of end-of-life discussions with ALS patients, highlighting the need for effective communication about end-of-life decision-making.

Consensus-based guidelines from Canada, Europe and the United States recommend discussing preferences for lifesustaining therapies and end-of-life care on a regular basis with ALS patients $(16,36,37)$. However, guidelines for discussions about end of life with ALS patients have not been published. Communication guidelines have focused on the disclosure of the ALS diagnosis, offering clinicians specific guidance for introducing and discussing the challenges of this rapidly progressing, neurodegenerative disease $(36,38,39)$.
Published reviews focusing on quality of care and quality of life (40), end-of-life management (41), and palliative care information needs of ALS patients (42) have also drawn attention to the importance of communication about end of life for people living with ALS. However, there is need for a structured, systematic, and evidence-informed approach to this communication (43). Given the recognition that research evidence is as important in palliative care as it is in other fields of medicine (44), this scoping review investigates the scope and nature of empirical articles on communication about end of life with ALS patients, identifies gaps, and provides a foundation for empirically-based, communication guidelines for discussions about end of life with ALS patients.

\section{METHODS}

\section{Identification of Research Question}

A team of experts from fields including neurology and health communication were consulted to identify goals and research questions for this scoping review. Identified goals were to understand the empirical evidence base, identify research gaps, determine research opportunities, and provide a foundation for clinically focused communication guidelines. Specifically, the review addressed two research questions: (1) What is the scope and nature of published research on ALS and health communication about end of life? And (2) what, if any, recommendations are made in primary research articles whose central focus is end-of-life communication with patients living with ALS?

\section{Design}

Scoping reviews are commonly undertaken when there is a broad question, a range of study designs, no prior knowledge synthesis on the topic, and an interest in identifying gaps and envisaging future research directions (45-48). The methodology used for this review was based on Arksey and O'Malley's five stages for scoping reviews: (i) identify the research question; (ii) develop the search strategy; (iii) apply inclusion and exclusion criteria to select articles; (iv) chart and collate the data; and (v) summarize and report the results (45). In accordance with recommendations for scoping reviews $(47,48)$, a quantitative, numerical summary analysis, followed by a qualitative thematic analysis of the subset of articles whose central focus was communication in the context of ALS and end of life was conducted. The discussion section completes the summary and reporting stage as it focuses on the meaning and implications of the study findings (47).

\section{Data Sources and Search Strategy}

An expert health sciences librarian developed search strategies for the following electronic databases: MEDLINE (Ovid), EMBASE (Ovid), PsycINFO, CINAHL (EBSCO), SCOPUS, Dissertations and Theses Global (Proquest), and Web of Science, and EMB Reviews (Ovid) including Cochrane Database of Systematic Reviews, ACP Journal Club, Database of Abstracts of Reviews of Effects, Cochrane Central Register of Controlled Trials, Cochrane Methodology Register, Health Technology Assessment, and NHS Economic Evaluation Database. The following legal databases 
were also searched: Westlaw, Heinonline and the Factiva subcategory "US law reviews and journals." Search algorithms used controlled vocabulary within databases and synonyms for "amyotrophic lateral sclerosis," "end of life," and "health communication." Date or other limits were not applied. Initial searches were completed in October 2015 and updated in January 2018. A second update was conducted in May 2021. At the time of the second update, all the EMB Reviews (Ovid) databases had been replaced by Cochrane Library (CDSR and Central Register of Controlled Trials). The search strategy used for Medline is included as a sample in Supplementary File 1; other detailed search strategies are available from the corresponding author.

\section{Application of Inclusion/Exclusion Criteria}

Article records, including titles and abstracts, were retrieved and uploaded to bibliographic management software (Endnote 7). For the initial search and 2018 update, four coders removed duplicates and applied the inclusion/exclusion criteria to the article records that met the search criteria. Articles meeting the following criteria were included: (1) reported primary quantitative and/or qualitative empirical data; (2) addressed end of life for people with ALS; (3) discussed health communication; and, (4) were published in the English language. Health communication was defined as per the Medical Subject Headings (MeSH) thesaurus: the transfer of information from experts in the medical and public health fields to patients and the public, and the study or use of communication strategies to inform and influence health-related decisions (49). All coders received training and discrepancies were resolved through discussion to consensus during the training period. Coders then screened $10 \%$ of the article records and inter-coder reliability was determined by calculating the Light's kappa coefficient in Microsoft Excel as 0.87 . Each coder independently screened one quarter of the remaining records. This same process was followed when assessing the full text articles. Based on $10 \%$ of the articles the Light's Kappa coefficient was calculated as 0.81 . Two coders completed the 2021 update. The Kappa coefficient was calculated as 0.99 for screening the article records and coding the included full text articles.

\section{Quantitative Data Extraction and Analysis}

Based on the research questions and expert input a web-based, standardized data extraction sheet was developed. Each selected article was coded for: bibliographic information, jurisdiction where the study was conducted, research design, study methods, participant population, sample size, quality of life and family burden, discussion of voluntary assisted death, and peripheral or primary focus on health communication. Three trained coders extracted data from the selected full text articles. The calculated Light's Kappa coefficient was 0.74. The Kappa coefficient for the 2021 update was 0.99 . Numerical summary analysis was conducted based on the data extracted to a priori categories $(47,50)$.

\section{Qualitative Analysis and Synthesis}

Qualitative, inductive analysis was conducted on the subset of articles that were coded during quantitative analysis as having primary focus on health communication (the "communication subset"). Based on the research questions and expert input, key concepts and themes were identified using an iterative approach. Discussion to consensus was achieved by working through a small sample of articles. One coder coded the communication subset; the second coder coded $10 \%$ of the articles. Based on this $10 \%$, the Kappa coefficient was assessed as 0.97 (initial and 2018 update) and 0.94 (2021 update) for the qualitative analysis. NVivo 10 software facilitated data organization and qualitative coding.

\section{RESULTS}

\section{Study Screening and Inclusion}

Literature searches returned 2,477 unique article records, of which 296 were potentially relevant and eligible for fulltext review. Of these, 211 met the review's inclusion criteria for quantitative analysis. (See Supplementary File 2 for list of included studies). One hundred and ten articles focused explicitly on health communication. These comprised the 'communication subset' and were included in qualitative thematic analysis (Figure 1).

\section{Quantitative Analysis of all Articles $(n=211)$}

\section{Distribution of Articles}

There was a modest upward trend in publications from 1991 to 2020 (Figure 2), with the majority of publications published after 2011 (51\%) and peaks in 2014 and 2015. Four articles from the first 4 months of 2021 met the inclusion criteria. The reviewed

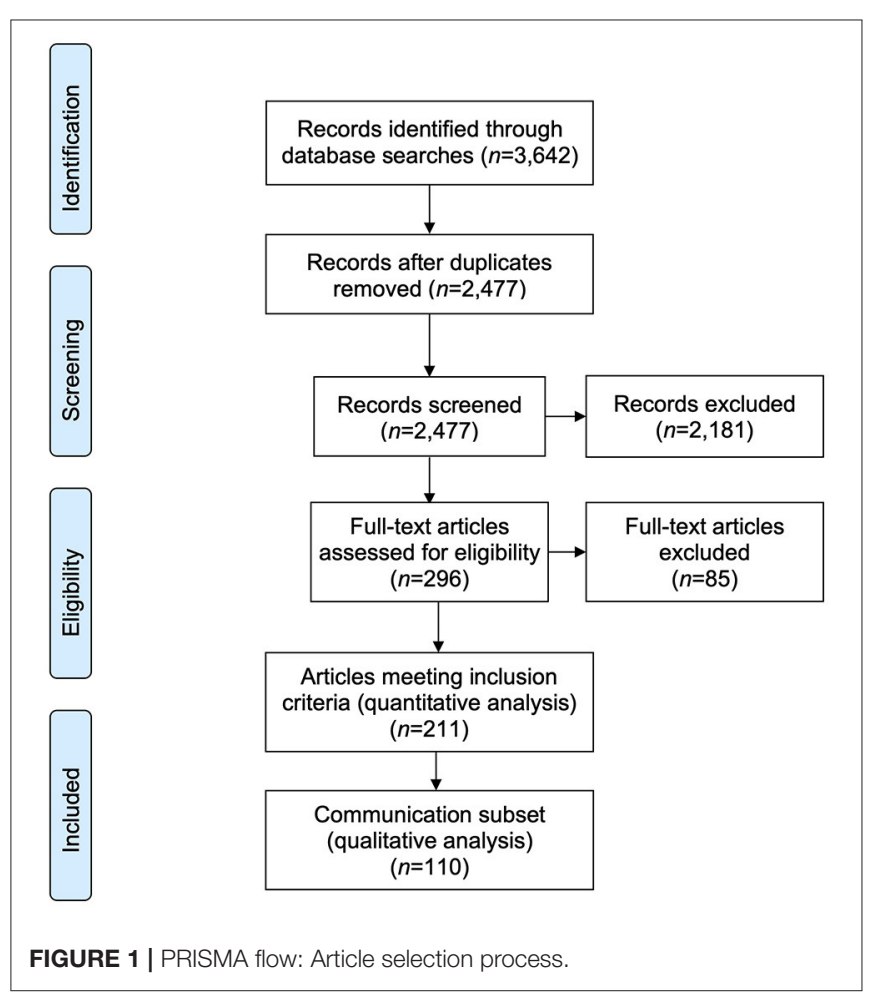




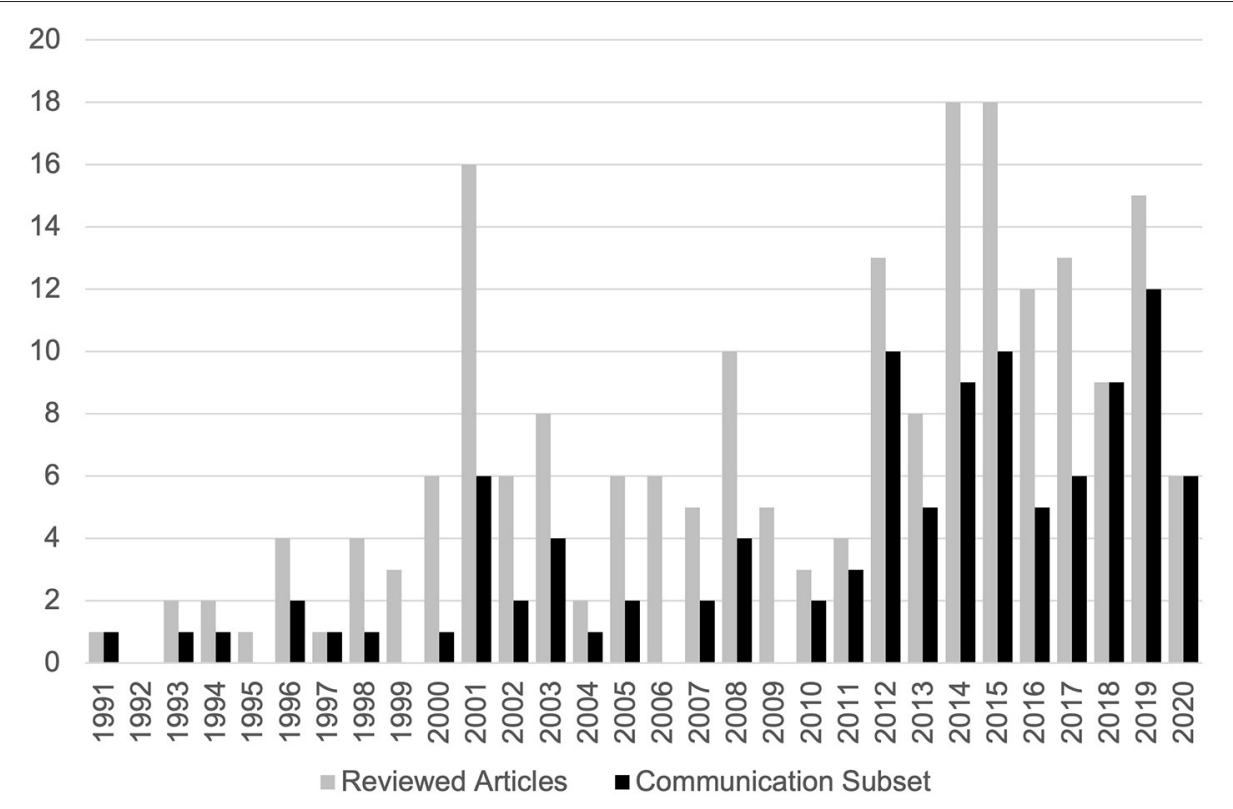

FIGURE 2 | Distribution of reviewed articles and communication subset by year.

TABLE 1 | Distribution by journal title.

\begin{tabular}{lcc}
\hline Journal title & Reviewed & Communication focus \\
\hline Neurology & 28 & 4 \\
Amyotrophic Lateral Sclerosis and & 28 & 13 \\
Frontotemporal Degeneration* & & 9 \\
Journal of the Neurological Sciences & 17 & 8 \\
Palliative Medicine & 10 & 3 \\
Journal of Neurology & 8 & 3 \\
Journal of Pain and Symptom & 7 & 4 \\
Management & 7 & \\
Palliative and Supportive Care & & \\
\hline
\end{tabular}

*formerly indexed as Amyotrophic Lateral Sclerosis and Other Motor Neuron Disorders (2000-2004) and Amyotrophic Lateral Sclerosis (2005-2012).

articles $(n=211)$ were published in 84 different journals. Articles in the communication subset $(n=110)$ were published in 60 different journals. Seven journals published more than five reviewed articles each and almost 50\% $(n=105)$ of the reviewed articles (Table 1). Reviewed articles were primarily published in journals identified by five non-exclusive Web of Science journal subject categories (Table 2). Eleven articles were published in journals not indexed by Web of Science.

\section{Article Characteristics}

Table 3 summarizes the general characteristics of the included articles $(n=211)$. In addition to the United States, European Union, United Kingdom, and Canada, studies were conducted in Japan, Taiwan, Singapore, Korean, Australia, and Israel. Studies used quantitative, qualitative, and mixed methods. Most included ALS patients or family members, with both
TABLE 2 | Distribution by Web of Science journal subject category.

\begin{tabular}{lc} 
Journal subject category & Reviewed articles $(\boldsymbol{n}=\mathbf{2 1 1})$ \\
\hline Clinical Neurology-SCIE* & 105 \\
Health Care Sciences \& Services-SCIE & 40 \\
Medicine, General \& Internal-SCIE & 19 \\
Public Environmental \& Occupational Health-SSCI ${ }^{\star *}$ & 19 \\
Health Policy \& Services-SSCI & 10 \\
Other ( $n=25$ subject categories) & 40 \\
\hline
\end{tabular}

* Science Citation Index.

** Social Science Citation Index.

groups being included in 69 articles. Study sample sizes ranged from two (a qualitative document analysis) to 1,636 (administrative data analysis). The 42 articles with healthcare professionals as participants included small interview-based studies (<35 participants), larger questionnaire-based studies (>100 participants), and studies that focused on care teams in multidisciplinary clinics.

\section{Quality of Life}

Of the 211 articles, 68\% $(n=144)$ addressed quality of life (QoL) as experienced by patients $(n=120)$, or the perspectives of family $(n=41)$ and healthcare professionals $(n=11)$ on patients' QoL. These articles addressed the physical domain $(n=116)$, psychological/emotional domain $(n=104)$, social functioning domain $(n=60)$, religious/spiritual domain $(n=41)$, and financial domain $(n=31) ; 107$ articles discussed more than one domain. 
TABLE 3 | Study characteristics.

\begin{tabular}{|c|c|}
\hline Study characteristic & $n=211(\%)$ \\
\hline \multicolumn{2}{|l|}{ Jurisdiction* } \\
\hline United States & $73(34.6 \%)$ \\
\hline European Union & $71(33.6 \%)$ \\
\hline United Kingdom & $23(10.9 \%)$ \\
\hline Canada & $16(7.6 \%)$ \\
\hline Other & $37(17.5 \%)$ \\
\hline \multicolumn{2}{|l|}{ Study design } \\
\hline Quantitative & $132(62.6 \%)$ \\
\hline Qualitative & $55(26.1 \%)$ \\
\hline Mixed methods & $24(11.4 \%)$ \\
\hline \multicolumn{2}{|l|}{ Study methods* } \\
\hline \multicolumn{2}{|l|}{ Quantitative methods } \\
\hline Questionnaire & $112(53.1 \%)$ \\
\hline Cohort study & 39 (18.5\%) \\
\hline Other quantitative methods ${ }^{\star \star}$ & $25(11.8 \%)$ \\
\hline Clinical trial & $7(3.3 \%)$ \\
\hline Case control & $7(3.3 \%)$ \\
\hline \multicolumn{2}{|l|}{ Qualitative methods } \\
\hline Interview & $61(28.9 \%)$ \\
\hline Other qualitative methods ${ }^{\star *}$ & $9(4.3 \%)$ \\
\hline Document analysis & $6(2.8 \%)$ \\
\hline Focus group & $6(2.8 \%)$ \\
\hline Case study & $2(0.9 \%)$ \\
\hline \multicolumn{2}{|l|}{ Participants ${ }^{*}$} \\
\hline ALS patients & $160(75.8 \%)$ \\
\hline Family members/informal caregivers & $94(44.5 \%)$ \\
\hline Health care professionals & 42 (19.9\%) \\
\hline General population & $3(1.4 \%)$ \\
\hline
\end{tabular}

${ }^{*}$ Articles from multiple jurisdictions or using multiple methods are included in each relevant category.

${ }^{* *}$ Articles using quantitative or qualitative methods not included in the data extraction sheet, for example, health economic analysis and chart review.

\section{Family Burden}

The articles $(n=82)$ that addressed family burden addressed burden associated with the psychological/emotional domain $(n=69)$, social functioning domain $(n=31)$, physical domain $(n=30)$, financial domain $(n=22)$, and unspecified domain $(n=28) ; 58$ articles addressed more than one domain. Three articles addressed the psychological/emotional burden associated with concerns about familial ALS genetic risk. Sixty-five articles addressed both QoL for patients living with ALS and family burden, and 20 articles identified changes in family dynamics as a factor in patient QoL and/or family burden.

\section{End of Life and Voluntary Assisted Dying}

One hundred and twenty-three articles included the views or perspectives of ALS patients, family members, and/or healthcare professionals about end-of-life choices or options (Table 4), including palliative care, withdrawal of treatment, palliative sedation, and voluntary assisted death.
The majority of articles focused on end-of-life options without discussing voluntary assisted death $(60.6 \% ; n=$ $77) ; 6.5 \%(n=8)$ articles focused on voluntary assisted death exclusively.

\section{Quantitative and Qualitative Analysis of the Health Communication Subset $(n=110)$}

Eighty-one articles within the health communication subset ( $n=110)$ highlighted the importance of discussions about end of life for people living with ALS. Twenty-eight articles noted the influence of communication on patient care, and 19 noted its influence on the therapeutic relationship between healthcare professionals and patients and/or their families. Fiftyfive articles discussed communication about specific end-oflife options; 13 noted voluntary assisted death. Thirty-three articles included discussion of symptom management at end of life, for example, nutritional or respiratory support. Themes identified in the communication subset included communication quality (communication barriers and facilitators) $(n=81)$, difficult conversations $(n=72)$, and functional communication challenges $(n=45)$ (Table 5).

Articles that addressed the quality of communication between patients with ALS, families and healthcare professionals noted facilitators $(n=40)$ and barriers $(n=57)$. Facilitators and barriers were characterized not only by communication style, but also by information substance (what is communicated) and sufficiency (enough information to meet patient need). As might be anticipated, for example, ALS patients and their families valued open and/or "honest" communication with health care professionals $(39,51,52,106)$. In addition, researchers exploring the experiences of ALS caregivers noted that a lack of empathic communication "left the participants feeling shocked, bewildered, angry and devastated" (53). However, this current analysis found that a greater number of articles highlighted the importance of meeting the information needs of patients and families. For example, researchers investigating decisions about life-sustaining treatments reported, "the provision of full information was paramount, which in some cases included providing information in different formats" (54), and neurologists who provided needed or desired information were rated more highly by family caregivers (55). Further, a reviewed study found that ALS patients who "lack communication, information, and clear answers from health providers" experienced "frustration and despair due to a limited life time" (56). Seventeen articles noted seeking information outside the medical system, including online, from interpersonal sources and/or from patient advocacy organizations $(18,51,54$, $57-67,118,119,148)$.

Of the 72 articles that addressed "difficult conversations," 38 noted avoidance of end-of-life discussions by ALS patients, their families, and/or healthcare professionals. Twenty-four articles focused on communicating an ALS diagnosis. Articles drawing attention to functional communication challenges related to a motor speech disorder $(n=45)$ primarily highlighted the severity of communication impairments $(n=27)$ and strategies to address speech loss $(n=22)$ (Table 5). 
TABLE 4 | Views represented in articles discussing end-of-life options and/or voluntary assisted death.

\begin{tabular}{|c|c|c|c|c|}
\hline$n=123(\%)$ & ALS patients & Family members & Health professionals & End-of-life options/voluntary assisted death \\
\hline 123 & 101 & 39 & 30 & End-of-life options discussed \\
\hline 77 & 61 & 29 & 20 & End-of-life options; not voluntary assisted death \\
\hline 38 & 33 & 7 & 9 & End-of-life options, including voluntary assisted death \\
\hline 8 & 7 & 3 & 1 & Voluntary assisted death; not other end-of-life options \\
\hline
\end{tabular}

\section{Recommendations}

Sixty-seven articles made "actionable" recommendations. These were represented by statements of "how" or "what" should be done to improve communication. Recommendations were thematically analyzed. For example, articles with a thematic focus on improving communication processes (actions and steps needed to communicate effectively) included recommendations for the timing of communication about end of life, potential communication mediums (visual, written, web-based), and collaboration between clinicians.

Recommendations in the analyzed articles focused on improving communication processes $(n=36)$, improving communication style $(n=21)$, and improving or changing the content of information communicated to ALS patients and their families $(n=21)$. The 2021 update resulted in one substantial change: 14 articles from 2018 to 2021 recommended 'more research' whereas only 4 articles between 1991 and 2017 made this recommendation. Fifteen articles noted a need for communication guidelines or standards, and 15 made a range of recommendations for improving the training of health professionals. A small number of articles specifically recommended shared decision-making $(n=5)$, use of decisionmaking aids $(n=4)$, and the importance of supporting the patient-caregiver relationship $(n=2)$.

Forty-seven articles directed recommendations to health care professionals; 25 did not specify who should carry out the recommended action; and 18 articles made recommendations for researchers. Actionable recommendations were also directed toward health systems $(n=9)$, medical educators $(n=8)$, ALS support organizations $(n=3)$, and family members of patients living with ALS $(n=3)$. Table 6 summarizes analysis of the recommendations found in the included articles.

\section{DISCUSSION}

\section{Main Findings of the Scoping Review}

This review identified a limited evidence base and lack of comprehensive recommendations for health communication about end of life with ALS patients. Despite increasing discussion and legalization of voluntary assisted death across jurisdictions (28-30) and its implications for ALS patients $(30,149,150)$, there has been only a modest increase over time in empirical investigations of communication about end of life for this population. Moreover, most of the reviewed articles addressed end-of-life communication as a peripheral focus of investigation. In keeping with other studies, this review highlights the need for generic communication skills, including empathy and relationship building (151-154). Findings, however, bring attention to the importance of providing substantive and sufficient disease-related information, including information about symptom management and assistive devices, when discussing end-of-life issues. For people living with ALS, decisions about symptom management, for example dyspnea or dysphagia, may change the natural disease trajectory as technologies introduced for symptom management become life-support technologies (16). Recommendations for communication about end of life with ALS patients primarily target health professionals, providing only general suggestions for improving communication rather than specific, actionable guidelines similar to published guidelines for disclosing an ALS diagnosis $(36,38,39)$. The following paragraphs discuss the scope of end-of-life, ALS-focused communication research, perceptions of communication quality, unique challenges for discussions of end of life with ALS patients, and a need for "actionable" communication recommendations that might guide effective communication in clinical practice.

The findings in this review highlight the multidisciplinary nature of health communication research and the concomitant challenge of finding a "home" for ALS-related communication research. Although advances with keyword searching and access to multiple databases mitigate some of these challenges, reviewed articles were published across a wide range of journals and were identified by heterogeneous and poorly standardized database subject headings (155-157). This may introduce challenges for clinicians seeking to find ALS-specific, evidence-based guidance for discussing end of life.

Quality of life for ALS patients and, to a lesser extent, family burden has been widely examined in the ALS literature. These themes appear prominently in the current review, with physical and psychological/emotional domains discussed most frequently as related to one another. For example, articles suggested that planning for end of life was influenced by fear of physical symptoms and of being a burden to loved ones $(33,158,159)$. Although communication about the physical aspects of end of life may be viewed as a central task for healthcare professionals, findings suggest, unsurprisingly, that psychological/emotional, social, religious, and even financial factors may also be important aspects of end-of-life communication. In addition to the psychological and emotional toll on ALS patients and their families, research demonstrates substantial emotional burden for healthcare professionals caring for people with terminal neurological disease (41). While patient voices were well represented in the review, articles were less likely to examine the perspectives of healthcare professionals. Given the role that 
TABLE 5 | Themes identified in the health communication subset.

\begin{tabular}{lcc}
\hline Themes & $\mathbf{N = 1 1 0 ( \% )}$ & References \\
\hline $\begin{array}{l}\text { Communication barriers } \\
\text { Insufficient information given about disease and/or assistive }\end{array}$ & $57(51.8 \%)$ & $(18,19,39,51-104)$ \\
devices & $31(28.2 \%)$ & $(18,52,54-58,60-63,65-67,69,74,75,79,81,83-85,87,89,90,92,96-98$, \\
Lack of options communicated by Health professionals (symptom & $14(12.7 \%)$ & $102,105)$ \\
management and/or end of life) & & $(51,55,58-60,68,71,74,77,86,93,96,97,103)$ \\
$\begin{array}{l}\text { Health professional is perceived to lack compassion } \\
\text { Patients and/or family perceives lack of respect or dignity }\end{array}$ & $9(8.2 \%)$ & $(18,53,55,64,70,73,84,88,97,102,103)$ \\
$\begin{array}{l}\text { Patients and/or family interest in ALS information limits } \\
\text { Communication }\end{array}$ & $6(5.5 \%)$ & $(53,55,56,59,60,65,88,102,103)$ \\
$\begin{array}{l}\text { Patients and/or family experiences negative emotion when } \\
\text { communicating with health professional }\end{array}$ & $4(3.6 \%)$ & $(19,63,66,69,82,87)$ \\
Health professional does not have the information to answer & $6(5.5 \%)$ & $(61,70,71,88)$ \\
question(s) & $9(8.2 \%)$ & $(65,70,72,91,98,103)$ \\
Health professional is reluctant to address end of life & $6(5.5 \%)$ & $(51,66,78,80,97-101)$ \\
Communication is "forced" by an individual or by disease & & $(39,70,91,95,97,104)$
\end{tabular}
progression

\section{Communication facilitators}

$40(36.4 \%)$

Health professional is perceived to be friendly or kind "Sufficient" information given about disease and/or assistive devices

Access to health professionals, for immediate information needs and ongoing communication or support

Patients and/or family feels satisfied with communication

Health professional is perceived to be empathetic and/or trustworthy

Open and/or honest communication

Patients and/or family feels respected

\section{Difficult conversations}

End-of-life discussion avoidance

Timing for difficult conversations

Delivering bad news, health professionals' perspectives

Health professional reluctance to address prognosis

Clinical education to prepare health professionals for difficult conversations

\section{Delivering the ALS diagnosis}

Method for delivering diagnosis

Badly communicated diagnosis

Effective communication of diagnosis

Skilled delivery of diagnosis is important

Functional communication challenges

Severity of communication impairment

Strategies to address speech loss, including AAC

Emotional and social impact of communication challenges

Impact of devices (e.g., ventilator) on communication

Effect of AAC on QoL
$21(19.1 \%)$

$25(22.7 \%)$

$16(14.5 \%)$

$8(7.3 \%)$

$6(5.5 \%)$

$4(3.6 \%)$

$4(3.6 \%)$

$72(65.5 \%)$

38 (34.5\%)

$39(35.5 \%)$

$16(14.5 \%)$

$6(5.5 \%)$

$13(11.8 \%)$

$25(22.7 \%)$

$13(11.8 \%)$

$11(10.0 \%)$

$5(4.5 \%)$

$5(4.5 \%)$

45 (40.9\%)

27 (24.5\%)

$22(20.0 \%)$

$13(11.8 \%)$

$7(6.4 \%)$

5 (4.5\%)

\author{
$57(51.8 \%)$ \\ $(39,70,91,95,97,104)$
}

$(18,19,33,39,51,52,54-57,59,61-63,68-70,72,73,76,80,81,83-85,91$, $92,96-98,103,106-114)$

$(18,39,48,49,55-59,70,71,78,79,83,89,90,95,96,101,115,116)$ $(18,39,52,54,55,57,62,63,68-70,80,81,84,91,92,96-98,103,111-$ $114,117)$

$(19,33,39,56,72,76,80,91,92,97,98,108-110,112,114)$

$(18,61,63,73,85,91,92,103)$

$(55,59,80,81,97,103)$

$$
(39,51,52,106)
$$

$(39,70,91,107)$

(18, 19, 33, 39, 51, 52, 54-56, 58, 60, 62-70, 72, 73, 75, 76, 78-82, 87, 89, $92,93,93-105,107-111,114,118-137)$

(18, 33, 39, 52, 54, 58, 60, 62-64, 68, 69, 75, 76, 82, 93, 94, 96-100, 103, $107,109,114,118-123,125,127,130,132,134,135)$

(19, 33, 51, 54, 62, 63, 76, 79, 87, 107, 108, 122, 124, 125, 127, 132, 133, 138) $(69,73,80,81,87,93,94,97,99-101,107,109,111,122,124)$

$(69,87,93,97,107,109)$

$(39,55,67,73,78,80,81,89,97-99,128,130)$

$(18,39,53,55,57,60-63,69,73,80-85,94,109,117,124,128,133,139,140)$

$(39,55,57,60,62,63,73,80,81,85,124,128,139)$

$(18,53,55,60,61,73,81,83,84,117,140)$

$(55,61,81,83,133)$

$(55,73,81,94,109)$

$(18,33,39,51,52,56-58,63,64,67,71,76-78,82,83,85,86,88,90,92-$ $94,98,102,105,108,113,114,117-119,127,132,134,138,139,141-147)$ $(18,33,51,52,56,58,63,64,71,76,77,83,86,88,92,93,98,108,117$, $132,134,138,141-145)$

$(39,51,52,56-58,67,71,85,86,88,92,105,108,113,114,117,119,134$, $145,146)$

$(52,56,71,82,86,88,92,113,114,117,118,134,143)$

$(52,67,71,92,117,127,145)$

$(52,67,71,88,94)$ 
TABLE 6 | Actionable recommendations for improving health communication $(n=110)$.

\begin{tabular}{|c|c|c|}
\hline $\begin{array}{l}\text { Recommendations (number } \\
\text { of articles) }\end{array}$ & Target group (number of articles) & Examples \\
\hline $\begin{array}{l}\text { Improve communication } \\
\text { practices and/or processes (36) }\end{array}$ & $\begin{array}{l}\text { Health professionals (28), Health systems } \\
\text { (8), ALS support organizations (2), Family } \\
\text { members (2), Unspecified (3) }\end{array}$ & $\begin{array}{l}\text { Use of advance directives and collaboration with other related practitioners } \\
\text { are recommended to enhance communication linked to psychological care } \\
\text { and informed consent. (76) }\end{array}$ \\
\hline $\begin{array}{l}\text { Improve communication style } \\
\text { (21) }\end{array}$ & $\begin{array}{l}\text { Health professionals (17), Medical } \\
\text { education (1), Unspecified (3) }\end{array}$ & Use language that patients and their families can understand. (92) \\
\hline $\begin{array}{l}\text { Improve or amend } \\
\text { communication content (21) }\end{array}$ & $\begin{array}{l}\text { Health professionals (14), Family members } \\
\text { (1), Unspecified (7) }\end{array}$ & $\begin{array}{l}\text {...fears of "choking to death" are unwarranted. This information should be } \\
\text { available to ALS patients at the time when ventilatory options are discussed. } \\
\text { (89) }\end{array}$ \\
\hline More research is needed (18) & Researchers (18) & $\begin{array}{l}\text {...qualitative research in this area is needed to fully understand ACP } \\
\text { [advance care planning] preferences and practices among patients... (129) }\end{array}$ \\
\hline $\begin{array}{l}\text { Communication guidelines or } \\
\text { standards needed (15) }\end{array}$ & $\begin{array}{l}\text { Health professionals (4), ALS support } \\
\text { organizations (1),, Medical education (1), } \\
\text { Researchers (1), Unspecified (12) }\end{array}$ & $\begin{array}{l}\text { More widely available guidelines for the provision of gastrostomy and advice } \\
\text { on the best way to impart information to patients and caregivers about } \\
\text { gastrostomy and NIV appear to be needed. (125) }\end{array}$ \\
\hline $\begin{array}{l}\text { Improve health professionals' } \\
\text { training (15) }\end{array}$ & $\begin{array}{l}\text { Medical education (8), Health professionals } \\
\text { (4), ALS support organizations (1), } \\
\text { Researchers (1), Unspecified (7) }\end{array}$ & $\begin{array}{l}\text { Medical educators must strive to understand their students' perspectives, } \\
\text { adapt their teaching so that they impart compassionate and clinically astute } \\
\text { end-of-life care practices... (78) }\end{array}$ \\
\hline $\begin{array}{l}\text { Facilitate shared } \\
\text { decision-making (5) }\end{array}$ & Health professionals (5), Health systems (1) & $\begin{array}{l}\text {... the patient and caregiver function as a team, and the caregiver should be } \\
\text { included in discussions on treatment and care. (75) }\end{array}$ \\
\hline Use decision-making aids (4) & Health professionals (1), Unspecified (3) & $\begin{array}{l}\text { Our study supports the view that PPC [preferred priorities for care] } \\
\text { document should also be offered to MND/ALS patients as a standard of } \\
\text { care. (121) }\end{array}$ \\
\hline $\begin{array}{l}\text { Improve the patient-caregiver } \\
\text { relationship (2) }\end{array}$ & $\begin{array}{l}\text { Health professionals (1), Family members } \\
\text { (1) }\end{array}$ & $\begin{array}{l}\text { Caregivers should take care not only of the patient, but also of themselves, } \\
\text { in order to offer adequate support to their loved ones. (60) }\end{array}$ \\
\hline
\end{tabular}

healthcare professionals play in discussing end of life with ALS patients, more research on healthcare professionals' perspectives is needed as a step toward developing guidance for end-oflife communication.

Voluntary assisted death, when discussed, was primarily contextualized within an overarching discussion of end-of-life options. Within the communication subset, very few articles noted assisted death. These findings may be an artifact of the lag between legislative changes and empirical investigation. They may also reflect a tendency toward symptom-driven communication rather than end-of-life discussions that are integrated into clinical care. For example, discussions about end of life may occur in tandem with decisions about initiating, continuing, and/or discontinuing life-sustaining interventions such as mechanical ventilation or enteral feeding tubes. Attitudes toward end-of-life options, including voluntary assisted death, vary across regions and cultures $(28,160,161)$. With high mobility within populations, increasing attention to the influence of culture and personal beliefs on advance care planning and decisions for people with ALS (41, 118, 120, 162), and increasing access to voluntary assisted death in many jurisdictions (28, 29), the need for patient-centered evidence and communication guidance is increasingly important for sensitive, effective communication about palliative care and end-of-life options.

The integral role of communication for end-of-life care is documented in the palliative care literature $(5,163,164)$. Yet, fewer than half of the selected articles focused explicitly on health communication. These articles-the communication subsetindicate that, despite the importance of online disease-related information (165-168) and support $(169,170)$ for ALS patients, healthcare professionals are critical information sources for patients and their families. This suggests an important role for professionals both in providing information about end of life, and helping people make sense of information from online sources. Although information needs have been identified as an important domain at the time of the ALS diagnosis (61, 165, 171), research is needed to identify and better understand the information that ALS patients and families want and need to make decisions that influence the disease course and end of life. For example, in contrast to cancer patients, life-sustaining interventions such as nutritional and respiratory support are considered "standard of care" for people living with ALS and are positively associated with improved quality of life $(172,173)$. Communication about accepting or forgoing such interventions is, therefore, particularly relevant to ALS (and, perhaps, other neurodegenerative disorders). It follows that information about the nuances and practicalities of palliative sedation for the withdrawal of such life-sustaining interventions is important for people with ALS and their families.

Many of the communication challenges identified by this review are not unique to people living with ALS. For example, both this review and the palliative care literature identifies healthcare professionals' reluctance to address prognosis and end-of-life discussion avoidance (41, 115, 174, 175); difficulties identifying appropriate times for conversations about end of life $(5,115,164)$; and the changing needs of patients (163). ALS, however, presents additional communication challenges. First, findings demonstrate that disclosing an ALS diagnosis is 
closely associated with discussions about end of life. Second, throughout the disease course, clinicians must effectively communicate both the chronic and terminal facets of ALS (107). For example, clinicians must guide patients and families through iterative decisions about initiating, maintaining and potentially withdrawing life-sustaining support for nutritional and respiratory needs. Finally, this analysis highlighted functional communication challenges. Almost all ALS patients experience motor speech disorder with disease progression $(176,177)$. This presents a unique challenge for those seeking to facilitate full and ongoing patient participation in discussions and decisions about end of life.

Thematic analysis makes an important contribution to understanding of the recommendations emerging from the analyzed articles. A small number of themes with specific application were identified (for example, four articles recommended the use of decision aids). However, most recommendations were limited to the specific interventions or gaps in care identified in individual articles and lacked the systematized guidance that is required to operationalize findings for clinical practice. Thematic analysis, however, draws attention to three aspects of communication: processes, style, and the content of communicated information. Findings indicated a primary need for improved communication processes, for example, discussion of end-of-life issues both early and incrementally throughout the disease trajectory $(52,121)$. Providing substantive information that meets the needs of patients and families was equally important to communication style in the recommendations. These findings draw attention to a need for focused empirical investigation of concrete, evidencebased communication strategies, and the development clinical communication guidelines for discussions about end of life with people living with ALS.

The paucity of focused, end-of-life communication research and the lack of progress in the development of empirically-based communication guidelines for ALS may reflect the tendency for research funding to target marketable interventions and therapies $(178,179)$. Even among non-profit ALS Societies the overwhelming majority of research funding is directed toward laboratory research, pharmacological interventions, and devices (180-182). Topics such as health communication, which reside at the intersection of Medicine and the Social Sciences, tend to receive limited funding.

\section{Implications for Research, Policy and Practice}

Empirically derived data about end-of-life discussions with ALS patients are primarily embedded in broadly focused investigations. Although there was a small increase in empirical articles, systematic investigation of communication about end of life is limited. The scarcity of research focused on communication, and the increasing number of empirical articles recommending more research in this area, may also reflect a need for proven research methodologies, as well as knowledge and expertise, that will address this evidence gap. Clinicians and researchers need to think of novel, patient-oriented methods to investigate both the communication practices of clinicians and the needs of ALS patients for information about end of life, both at the time of diagnosis and throughout the disease course. Investigations should yield specific, actionable recommendations for translation into policy and practice. This will provide a foundation for developing guidelines supporting end-of-life communication between health professionals and ALS patients and their families.

As discussed, findings may reflect policies and practices that direct research funding to marketable interventions and therapies. Despite the importance of these activities, communication is critical to the clinical management of ALS. Policies that promote the funding of communication research will provide a foundation for developing an evidence-base for compassionate, effective, and ethical communication about end of life, as well as evidence-based communication training in educational institutions and via continuing education for health professionals who care for ALS patients.

Finally, this review has implications for medical practitioners. The wide range of journals publishing research in this area of investigation may compromise access for practicing clinicians. Highly ranked journals that are specific to neurology and palliative care should seek to provide a home for this body for research that represents both the science and "art" of medicine. Further, this review draws attention to communication quality as mediated not only by core communication skills, but also by information substance and sufficiency. While emotional connection is important, the clinical expertise and information communicated by health professionals builds trust and "ownership" of care decisions $(181,182)$.

Clinical discussion of issues related to end of life has substantial impact on care and facilitates compliance with patients' wishes (169). Actionable recommendations and guidance are needed to support clinicians caring for patients with ALS. This is particularly important because ALS specialists and multidisciplinary ALS clinics are concentrated in large urban centers that may become inaccessible with disease progression. ALS patients frequently begin to rely on support from palliative and community physicians at a time when they need expert and nuanced information. Developing a strong empirical foundation and end-of-life communication guidance will support both specialists and non-specialists as they iteratively discuss lifesustaining therapies and end-of-life issues with ALS patients and their families.

\section{Strengths and Limitations}

This investigation followed standard methodological recommendations for scoping reviews, as well as Levac et al.'s recommendations to include both numerical summary analysis and qualitative content analytical techniques when summarizing and reporting results $(45,47,48)$. Recommendations to consider the review's implications within the broader contexts of research, policy and practice were also followed (47).

A primary strength of this review is the focus on primary research articles. Although many review and commentary articles that may provide insight into end-of-life communication were excluded, this review makes an important contribution by 
documenting the paucity of empirical evidence in this area of investigation. Better understanding of the scope and nature of the evidence, both quantitative and qualitative, provides a starting point for systematically addressing evidence gaps. Further, because the review included all empirical articles available in the databases without time restriction, these data meet the study objectives and provide an overarching view of this research area.

There are limitations to this review. Critical appraisal of articles was limited to the application of inclusion/exclusion criteria. For example, articles that did not report primary quantitative and/or qualitative empirical data were excluded. The rigor of research processes within individual studies was not evaluated.Restriction to articles published in the English language presents another limitation. Communication, particularly about end of life, is rooted in cultural expectations and practice. Some of the review's outcomes could, therefore, be an artifact of the language restriction.

Finally, despite the profound impact of legislative changes on end-of-life decisions for ALS patients $(68,122,150,183)$, the heterogenous methods used in the fields of Medicine and Law presented a methodological limitation. Whereas empirical data are central to high quality evidence in scientific fields such as Neurology (184), legal research focuses on doctrinal and comparative analysis of authoritative texts with reasoning and conceptual analysis as an indicator of quality $(116,185)$. Therefore, articles published in legal journals did not meet study inclusion criteria. Although scoping review methodology facilitates review of articles with varying research designs (45), further methodological development is needed to facilitate review and analysis of high-quality evidence emerging from the disparate research traditions of Medicine and Law.

\section{CONCLUSION}

This review demonstrates a small increase in empirical articles discussing end-of-life communication with people living with ALS (1991-May 2021). Most reviewed articles were published in clinical neurology journals. However, the articles were published in large number of different journals with only a small number published in each. Overall, communication about the end of life remains a peripheral part of more broadly focused investigations. This review found that generic communication skills, such as expressing empathy, were important; however, information substance and sufficiency was central to high quality, effective health communication. Recommendations for clinical communication focused on communication processes, style, and content, but lacked systematic guidance. Despite the

\section{REFERENCES}

1. Australian Commission on Safety and Quality in Health Care (ACSQHC). National Consensus Statement: Essential elements for safe and high-quality end-of-life care. Sydney NSW: ACSQHC (2015). Available online at: https:// www.safetyandquality.gov.au/publications-and-resources/resource-library/ national-consensus-statement-essential-elements- safe-and-high-qualityend-life-care (accessed May 22, 2020). absence of communication guidelines for end of life, practice recommendations for the management of ALS encourage clinicians to discuss life-sustaining therapies and end of life with ALS patients $(16,36,37)$. This review supports these recommendations by highlighting the need for focused, empirical investigation of best practices for end-of-life communication. This will provide a foundation for evidence-based, ALSspecific guidelines for communication about the end of life. Particularly with increasing options at end of life, actionable recommendations and guidance is needed to support ALS clinicians as they iteratively discuss life-sustaining therapies and end-of-life issues with patients and families.

\section{DATA AVAILABILITY STATEMENT}

The raw data supporting the conclusions of this article will be made available by the authors, without undue reservation.

\section{AUTHOR CONTRIBUTIONS}

TB and WJ conceived the original study and developed the design and methods. SC prepared and executed the search strategy. WL and SG screened studies for inclusion and carried out data extraction for quantitative analysis and qualitative data analysis. SG and WL conducted the synthesis with input from TB and WJ. SG drafted the manuscript with contribution from WL, TB, and WJ. All authors contributed to the article and approved the submitted version.

\section{FUNDING}

The author(s) disclosed receipt of the following financial support for the research, authorship and/or publication of this article: James and Jeanie Brown ALS Research Fund, Edmonton, Canada.

\section{ACKNOWLEDGMENTS}

The authors gratefully acknowledge Mark Bieber, Caitlin Vail, Angela Lee, and Mackenzie Moir for their contributions to data analysis. We are also grateful for funding from the James and Jeanie Brown ALS Research Fund, Edmonton, Canada.

\section{SUPPLEMENTARY MATERIAL}

The Supplementary Material for this article can be found online at: https://www.frontiersin.org/articles/10.3389/fneur. 2021.683197/full\#supplementary-material
2. Clayton JM, Hancock KM, Butow PN, Tattersall MHN, Currow DC. Clinical practice guidelines for communicating prognosis and end-of-life issues with adults in the advanced stages of a life-limiting illness, and their caregivers. Med J Aust. (2007) 186:S77. doi: 10.5694/j.1326-5377.2007.tb01100.x

3. Heyland DK, Cook DJ, Rocker GM, Dodek PM, Kutsogiannis DJ, Skrobik Y, et al. Defining priorities for improving end-of-life care in Canada. CMAJ. [2010] 182:E747-52. doi: 10.1503/cmaj.1 00131 
4. Parker SM, Clayton JM, Hancock K, Walder S, Butow PN, Carrick S, et al. A systematic review of prognostic/end-of-life communication with adults in the advanced stages of a life-limiting illness: patient/caregiver preferences for the content, style, and timing of information. J Pain Symptom Manage. (2007) 34:81-93. doi: 10.1016/j.jpainsymman.2006.09.035

5. Pino M, Parry R, Land V, Faull C, Feathers L, Seymour J. Engaging terminally ill patients in end of life talk: how experienced palliative medicine doctors navigate the dilemma of promoting discussions about dying. PLOS ONE. (2016) 11. doi: 10.1371/journal.pone.0156174

6. Hardiman O, Al-Chalabi A, Chio A, Corr EM, Logroscino G, Robberecht W, et al. Amyotrophic lateral sclerosis. Nat Rev Dis Primer. [2017] 3:17071. doi: 10.1038/nrdp.2017.85

7. Longinetti E, Fang F. Epidemiology of amyotrophic lateral sclerosis: an update of recent literature. Curr Opin Neurol. (2019) 32:7716. doi: 10.1097/WCO.0000000000000730

8. Hardiman O, Al-Chalabi A, Brayne C, Beghi E, Berg LH. van den, Chio A, et al. The changing picture of amyotrophic lateral sclerosis: lessons from European registers. J Neurol Neurosurg Psychiatry. [2017] 88:55763. doi: 10.1136/jnnp-2016-314495

9. Brott $\mathrm{T}$, Hocking C, Paddy A. occupational disruption: living with motor neurone disease. Br J Occup Ther. (2007) 70:2431. doi: $10.1177 / 030802260707000107$

10. Brown J, Addington-Hall J. How people with motor neurone disease talk about living with their illness: a narrative study. J Adv Nurs. (2008) 62:2008. doi: 10.1111/j.1365-2648.2007.04588.x

11. Harris DA. Lived-through past, experienced present, anticipated future: Understanding "existential loss" in the context of life-limiting illness. Palliat Support Care. (2015) 13:1579-94. doi: 10.1017/S1478951515000620

12. Ozanne A, Graneheim UH. Understanding the incomprehensible - patients' and spouses' experiences of comprehensibility before, at and after diagnosis of amyotrophic lateral sclerosis. Scand J Caring Sci. (2018) 32:66371. doi: $10.1111 /$ scs. 12492

13. Chio A, Logroscino G, Hardiman O, Swingler R, Mitchell D, Beghi E, et al. Prognostic factors in ALS: A critical review. Amyotroph Lateral Scler Off Publ World Fed Neurol Res Group Mot Neuron Dis. [2009] 10:31023. doi: 10.3109/17482960802566824

14. Traxinger K, Kelly C, Johnson BA, Lyles RH, Glass JD. Prognosis and epidemiology of amyotrophic lateral sclerosis. Neurol Clin Pract. (2013) 3:313-20. doi: 10.1212/CPJ.0b013e3182a1b8ab

15. Miller RG, Jackson CE, Kasarskis EJ, England JD, Forshew D, Johnston W, et al. Practice Parameter update: The care of the patient with amyotrophic lateral sclerosis: Drug, nutritional, and respiratory therapies (an evidence-based review): Report of the Quality Standards Subcommittee of the American Academy of Neurology. Neurology. (2009) 73:121826. doi: 10.1212/WNL.0b013e3181bc0141

16. Shoesmith C, Abrahao A, Benstead T, Chum M, Dupre N, Izenberg A, et al. Canadian best practice recommendations for the management of amyotrophic lateral sclerosis. CMAJ Can Med Assoc J. (2020) 192:E145368. doi: $10.1503 / \mathrm{cmaj} .191721$

17. Oliver DJ. Palliative care for patients with motor neurone disease: current challenges. Degener Neurol Neuromuscul Dis. (2016) 6:6572. doi: $10.2147 /$ DNND.S85103

18. Hogden A, Greenfield D, Nugus P, Kiernan MC. What influences patient decision-making in amyotrophic lateral sclerosis multidisciplinary care? A study of patient perspectives. Patient Prefer Adherence. (2012) 6:82938. doi: 10.2147/PPA.S37851

19. Lemoignan J, Ells C. Amyotrophic lateral sclerosis and assisted ventilation: How patients decide. Palliat Support Care. (2010) 8:207-13. doi: 10.1017/S1478951510000027

20. Munroe CA, Sirdofsky MD, Kuru T, Anderson ED. End-of-Life Decision Making in 42 Patients With Amyotrophic Lateral Sclerosis. Respir Care. (2007) 52:996-9.

21. Murray L, Butow PN. Advance care planning in motor neuron disease: A systematic review. Palliat Support Care. (2016) 14:411-32. doi: 10.1017/\$1478951515001066

22. Sloan R, Borasio GD. "Communication: Breaking the News," In: Oliver D, Borasio GD, editors. W Palliative care in amyotrophic lateral sclerosis: from diagnosis to bereavement. Johnston. Oxford: Oxford University Press.
23. Long R, Havics B, Zembillas M, Kelly J, Amundson M. Elucidating the endof-life experience of persons with amyotrophic lateral Sclerosis. Holist Nurs Pract. (2019) 33:3-8. doi: 10.1097/HNP.0000000000000301

24. Locock L, Ziebland S, Dumelow C. Biographical disruption, abruption and repair in the context of Motor Neurone Disease. Sociol Health Illn. (2009) 31:1043-58. doi: 10.1111/j.1467-9566.2009.01176.x

25. Locock L, Mazanderani F, Powell J. Metaphoric language and the articulation of emotions by people affected by motor neurone disease. Chronic Illn. (2012) 8:201-13. doi: 10.1177/1742395312443390

26. Halperin EC. Military metaphors and the consequences of the language of cancer. Pract Radiat Oncol. (2017) 7:1-3. doi: 10.1016/j.prro.2016.06.002

27. Semino E, Demjén Z, Demmen J, Koller V, Payne S, Hardie A, et al. The online use of Violence and Journey metaphors by patients with cancer, as compared with health professionals: a mixed methods study. BMJ Support Palliat Care. (2017) 7:60-6. doi: 10.1136/bmjspcare-2014-000785

28. Castro MPR de, Antunes GC, Marcon LMP, Andrade LS, Rückl S, Andrade VLÂ, et al. Euthanasia and assisted suicide in western countries: a systematic review. Rev Bioét. (2016) 24:355-67. doi: 10.1590/1983-80422016242136

29. Dyer O, White C, Rada AG. Assisted dying: law and practice around the world. BMJ. (2015) 351:h4481. doi: 10.1136/bmj.h4481

30. Russell JA. Physician-hastened-death in patients with progressive neurodegenerative or neuromuscular disorders. Semin Neurol. (2018) 38:522-32. doi: $10.1055 / \mathrm{s}-0038-1668080$

31. Bascom PB. Tolle SW. Responding to requests for physician-assisted suicide: these are uncharted waters for both of us. JAMA. (2002) 288:918. doi: 10.1001/jama.288.1.91

32. Baumrucker SJ. Amyotrophic lateral sclerosis and physician assisted suicide. Am J Hosp Palliat Med. (2006) 23:332-7. doi: 10.1177/1049909106290940

33. Maessen M, Veldink JH, Onwuteaka-Philipsen BD, Hendricks HT, Schelhaas HJ, Grupstra HF, et al. Euthanasia and physician-assisted suicide in amyotrophic lateral sclerosis: a prospective study. J Neurol. (2014) 261:1894901. doi: $10.1007 / \mathrm{s} 00415-014-7424-6$

34. Rodriguez v Attorney of British Columbia (AG), 3 SCR 519 (1993).

35. Carter v Canada (Attorney General), 2015 SCC 5, 1 SCR 331 (2015).

36. Andersen PM, Abrahams S, Borasio GD, Carvalho M de, Chio A, Damme PV, et al. EFNS guidelines on the Clinical Management of Amyotrophic Lateral Sclerosis (MALS) - revised report of an EFNS task force. Eur J Neurol. (2012) 19:360-75. doi: 10.1111/j.1468-1331.2011.03501.x

37. Miller RG, Brooks BR, Swain-Eng RJ, Basner RC, Carter GT, Casey P, et al. Quality improvement in neurology: Amyotrophic lateral sclerosis quality measures. Neurology. (2013) 81:213640. doi: 10.1212/01.wnl.0000437305.37850.f9

38. Chiò A, Borasio GD. Breaking the news in amyotrophic lateral sclerosis. Amyotroph Lateral Scler Other Motor Neuron Disord. (2004) 5:195201. doi: 10.1080/14660820310017326

39. Seeber AA, Pols AJ, Hijdra A, Grupstra HF, Willems DL, Visser M de. Experiences and reflections of patients with motor neuron disease on breaking the news in a two-tiered appointment: a qualitative study. $B M J$ Support Palliat Care. (2019) 9:e8-e8. doi: 10.1136/bmjspcare-2015-000977

40. Mitsumoto H. "The clinical features and prognosis of amyotrophic lateral sclerosis." In: H. Mitsumoto editors. Amyotrophic Lateral Sclerosis. New York, NY: Demos Medical Publishing. p. 40-85.

41. Connolly S, Galvin M, Hardiman O. End-of-life management in patients with amyotrophic lateral sclerosis. Lancet Neurol. (2015) 14:435-42. doi: 10.1016/S1474-4422(14)70221-2

42. Gillespie J, Przybylak-Brouillard A, Watt CL. The palliative care information needs of patients with amyotrophic lateral sclerosis and their informal caregivers: a scoping review. J Pain Symptom Manage. (2021) S0885392421002323. doi: 10.1016/j.jpainsymman.2021.03.008

43. Zehm A, Hazeltine AM, Greer JA, Traeger L, Nelson-Lowe M, Brizzi K. Jacobsen J. Neurology clinicians' views on palliative care communication: "How do you frame this?". Neurol Clin Pract. (2020) 10:527-34. doi: 10.1212/CPJ.0000000000000794

44. Bruera E. On Third Base but not Home Yet. J Palliat Med. (2008) 11:5659. doi: $10.1089 /$ jpm.2008.9924

45. Arksey H, O'Malley L. Scoping studies: toward toward a methodological framework. Int J Soc Res Methodol. (2005) 8:19-32. doi: 10.1080/1364557032000119616 
46. Ehrich K, Freeman GK, Richards SC, Robinson IC, Shepperd S. How to do a scoping exercise: continuity of care. Res Policy Plan. (2002) 20:259. Available online at: https://www.evidence.nhs.uk/document?id=1631198\& returnUrl=Search\%3Fq\%3Dfield\%2Bteam\&q=field+team

47. Levac D, Colquhoun H, O'Brien KK. Scoping studies: advancing the methodology. Implement Sci. (2010) 5:69. doi: 10.1186/1748-5908-5-69

48. Colquhoun HL, Levac D, O’Brien KK, Straus S, Tricco AC, Perrier L, et al. Scoping reviews: time for clarity in definition, methods, and reporting. J Clin Epidemiol. (2014) 67:1291-4. doi: 10.1016/j.jclinepi.2014.03.013

49. Medical Subject Headings-Health Communication. Available online at: https://meshb.nlm.nih.gov/record/ui?name=Health\%20Communication (accessed February 24, 2021).

50. Neuendorf KA. The content analysis guidebook. Second edition. Los Angeles: SAGE. (2017). doi: 10.4135/9781071802878

51. Young JM, Marshall CL, Anderson EJ. Amyotrophic lateral sclerosis patients' perspectives on use of mechanical ventilation. Health Soc Work. (1994) 19:253-60. doi: 10.1093/hsw/19.4.253

52. Silverstein MD, Stocking CB, Antel JP, Beckwith J, Roos RP, Siegler M. Amyotrophic lateral sclerosis and life-sustaining therapy: patients' desires for information, participation in decision making, and life-sustaining therapy. Mayo Clin Proc. (1991) 66:906-13. doi: 10.1016/S0025-6196(12)61577-8

53. Aoun SM, Connors SL, Priddis L, Breen LJ, Colyer S. Motor Neurone Disease family carers' experiences of caring, palliative care and bereavement: An exploratory qualitative study. Palliat Med. (2012) 26:842-50. doi: 10.1177/0269216311416036

54. Martin NH, Lawrence V, Murray J, Janssen A, Higginson I, Lyall R, et al. Decision Making About Gastrostomy and Noninvasive Ventilation in Amyotrophic Lateral Sclerosis. Qual Health Res. (2016) 26:136681. doi: $10.1177 / 1049732315583661$

55. Aoun SM, Breen LJ, Oliver D, Henderson RD, Edis R, O'Connor M, et al. Family carers' experiences of receiving the news of a diagnosis of Motor Neurone Disease: A national survey. J Neurol Sci. (2017) 372:14451. doi: 10.1016/j.jns.2016.11.043

56. Rosengren K, Gustafsson I, Jarnevi E. Every Second Counts: Women's Experience of Living With ALS in the End-of-Life Situations. Home Health Care Manag Pract. (2015) 27:76-82. doi: 10.1177/1084822314547961

57. Kübler A, Winter S, Ludolph AC, Hautzinger $M$, Birbaumer N. Severity of depressive symptoms and quality of life in patients with amyotrophic lateral sclerosis. Neurorehabil Neural Repair. (2005) 19:18293. doi: 10.1177/1545968305276583

58. Stavroulakis T, Baird WO, Baxter SK, Walsh T, Shaw PJ, McDermott CJ. Factors influencing decision-making in relation to timing of gastrostomy insertion in patients with motor neurone disease. BMJ Support Palliat Care. (2014) 4:57-63. doi: 10.1136/bmjspcare-2013000497

59. Kim S, Chung SE, Lee S, Park J, Choi S, Kim S. Experience of complementary and alternative medicine in patients with amyotrophic lateral sclerosis and their families: A qualitative study. Amyotroph Lateral Scler Front Degener. (2016) 17:191-7. doi: 10.3109/21678421.2015.11 25504

60. Cipolletta S, Amicucci L. The family experience of living with a person with amyotrophic lateral sclerosis: A qualitative study. Int J Psychol. (2015) 50:288-94. doi: 10.1002/ijop.12085

61. Chiò A, Montuschi A, Cammarosano S, Mercanti SD, Cavallo E, Ilardi A, et al. ALS patients and caregivers communication preferences and information seeking behavior. Eur J Neurol. (2008) 15:55-60. doi: 10.1111/j.1468-1331.2007.02000.x

62. Hogden A, Greenfield D, Nugus P, Kiernan MC. Engaging in patient decision-making in multidisciplinary care for amyotrophic lateral sclerosis: the views of health professionals. Patient Prefer Adherence. (2012) 6:691701. doi: 10.2147/PPA.S36759

63. Hogden A, Greenfield D, Nugus P, Kiernan MC. Development of a model to guide decision making in amyotrophic lateral sclerosis multidisciplinary care. Health Expect Int J Public Particip Health Care Health Policy. (2015) 18:1769-82. doi: 10.1111/hex.12169

64. Kenny RW. The death of Loving: maternal identity as moral constraint in a narrative testimonial advocating physician assisted suicide. Health Commun. (2002) 14:243-70. doi: 10.1207/S15327027HC1402_5
65. Bužgová R, Kozáková R, Juríčková L. The unmet needs of patients with progressive neurological diseases in the czech republic: a qualitative study. J Palliat Care. (2019) 34:38-46. doi: 10.1177/0825859718800489

66. Kukulka K, Washington KT, Govindarajan R, Mehr DR. Stakeholder perspectives on the biopsychosocial and spiritual realities of living with ALS: implications for palliative care teams. Am J Hosp Palliat Med. (2019) 36:851-7. doi: 10.1177/1049909119834493

67. Munan M, Luth W, Genuis SK, Johnston WS, MacIntyre E. Transitions in Amyotrophic Lateral Sclerosis: Patient and Caregiver Experiences. Can J Neurol Sci J Can Sci Neurol. (2020) 1-8. doi: 10.1017/cjn.2020.240

68. Kühnlein P, Kübler A, Raubold S, Worrell M, Kurt A, Gdynia H-J, et al. Palliative care and circumstances of dying in German ALS patients using non-invasive ventilation. Amyotroph Lateral Scler. (2008) 9:918. doi: 10.1080/17482960701830495

69. van Eenennaam RM, Kruithof WJ, van Es MA, Kruitwagen-van Reenen ET, Westeneng H-J, Visser-Meily JMA, et al. Discussing personalized prognosis in amyotrophic lateral sclerosis: development of a communication guide. BMC Neurol. (2020) 20:446. doi: 10.1186/s12883-020-02004-8

70. Nolan MT, Kub J, Hughes MT, Terry PB, Astrow AB, Carbo CA, et al. Family health care decision making and self-efficacy with patients with ALS at the end of life. Palliat Support Care. (2008) 6:27380. doi: 10.1017/S1478951508000412

71. Bach JR. Amyotrophic lateral sclerosis. Communication status and survival with ventilatory support. Am J Phys Med Rehabil. (1993) 72:3439. doi: 10.1097/00002060-199312000-00002

72. Sancho J, Servera E, Díaz JL, Bañuls P, Marín J. Home tracheotomy mechanical ventilation in patients with amyotrophic lateral sclerosis: causes, complications and 1-year survival. Thorax. (2011) 66:94852. doi: 10.1136/thx.2011.160481

73. Schellenberg KL, Schofield SJ, Fang S, Johnston WS. Breaking bad news in amyotrophic lateral sclerosis: The need for medical education. Amyotroph Lateral Scler Front Degener. (2014) 15:47-54. doi: 10.3109/21678421.2013.843711

74. Stutzki R, Schneider U, Reiter-Theil S, Weber M. Attitudes toward assisted suicide and life-prolonging measures in Swiss ALS patients and their caregivers. Front Psychol. (2012) 3. doi: 10.3389/fpsyg.2012.00443

75. Trail M, Nelson ND, Van JN, Appel SH, Lai EC, A. study comparing patients with amyotrophic lateral sclerosis and their caregivers on measures of quality of life, depression, and their attitudes toward treatment options. J Neurol Sci. (2003) 209:79-85. doi: 10.1016/S0022-510X(03)00003-0

76. Ushikubo M, Okamoto K. Circumstances surrounding death and nursing difficulties with end-of-life care for individuals with ALS in central Japan. Int J Palliat Nurs. (2012) 18:554-60. doi: 10.12968/ijpn.2012.18.11.554

77. Vitacca M, Vianello A. Scientific Group on Respiratory Intensive Care of the Italian Association of Hospital Pulmonologists. Respiratory outcomes of patients with amyotrophic lateral sclerosis: an Italian nationwide survey. Respir Care. (2013) 58:1433-41. doi: 10.4187/respcare.02236

78. Warner TD, Roberts LW, Smithpeter M, Rogers M, Roberts B, McCarty $\mathrm{T}$, et al. Uncertainty and opposition of medical students toward assisted death practices. J Pain Symptom Manage. (2001) 22:65767. doi: 10.1016/S0885-3924(01)00314-1

79. Zhang L, Sanders L, Fraser RJL. Nutritional support teams increase percutaneous endoscopic gastrostomy uptake in motor neuron disease. World J Gastroenterol. (2012) 18:6461-6467. doi: 10.3748/wjg.v18.i44.6461

80. Aoun SM, Breen LJ, Edis R, Henderson RD, Oliver D, Harris R, et al. Breaking the news of a diagnosis of motor neurone disease: A national survey of neurologists' perspectives. J Neurol Sci. (2016) 367:36874. doi: 10.1016/j.jns.2016.06.033

81. Aoun SM, Breen LJ, Howting D, Edis R, Oliver D, Henderson R, et al. Receiving the news of a diagnosis of motor neuron disease: What does it take to make it better? Amyotroph Lateral Scler Front Degener. (2016) 17:168-78. doi: 10.3109/21678421.2015.1111907

82. Gale C. Assisting patients with motor neurone disease to make decisions about their care. Int J Palliat Nurs. (2015) 21:251-5. doi: 10.12968/ijpn.2015.21.5.251

83. Bolmsjö I, Hermerén G. Interviews with patients, family, and caregivers in amyotrophic lateral sclerosis: comparing needs. J Palliat Care. (2001) 17:236-40. doi: 10.1177/082585970101700403 
84. Bolmsjö I, Hermérn G. Conflicts of interest: experiences of close relatives of patients suffering from amyotrophic lateral sclerosis. Nurs Ethics. (2003) 10:186-98. doi: 10.1191/0969733003ne593oa

85. Foley G, Timonen V, Hardiman O. Understanding psychosocial processes underpinning engagement with services in motor neurone disease: a qualitative study. Palliat Med. (2014) 28:318-25. doi: 10.1177/0269216313512013

86. Hayashi H, Oppenheimer EA, ALS. patients on TPPV: totally locked-in state, neurologic findings and ethical implications. Neurology. (2003) 61:1357. doi: 10.1212/01.WNL.0000069925.02052.1F

87. Hubbard G, McLachlan K, Forbat L, Munday D. Recognition by family members that relatives with neurodegenerative disease are likely to die within a year: A meta-ethnography. Palliat Med. (2012) 26:10822. doi: $10.1177 / 0269216311402712$

88. Jeppesen J, Rahbek J, Gredal O, Hansen HP. How narrative journalistic stories can communicate the individual's challenges of daily living with amyotrophic lateral sclerosis. Patient. (2015) 8:41-9. doi: 10.1007/s40271-014-0088-6

89. Kaub-Wittemer D, Steinbüchel N. von, Wasner M, Laier-Groeneveld G, Borasio GD. Quality of life and psychosocial issues in ventilated patients with amyotrophic lateral sclerosis and their caregivers. J Pain Symptom Manage. (2003) 26:890-6. doi: 10.1016/S0885-3924(03)00323-3

90. Krivickas LS, Shockley L, Mitsumoto H. Home care of patients with amyotrophic lateral sclerosis (ALS). J Neurol Sci. (1997) 152 Suppl 1:S8289. doi: 10.1016/S0022-510X(97)00251-7

91. Larsson BJ, Fröjd C, Nordin K, Nygren I. Relatives of patients with amyotrophic lateral sclerosis: Their experience of care and support. Palliat Support Care. (2015) 13:1569-77. doi: 10.1017/S1478951515000188

92. McKelvey M, Beukelman D, Kawai N, Evans D. Nine suggestions for the professional support of persons with amyotrophic lateral sclerosis as recounted by surviving spouses: a phenomenological study. Perspect Augment Altern Commun. (2013) 22:120-4. doi: 10.1044/aac22.2.120

93. Moss AH, Oppenheimer EA, Casey P, Cazzolli PA, Roos RP, Stocking $\mathrm{CB}$, et al. Patients with amyotrophic lateral sclerosis receiving long-term mechanical ventilation. Advance care planning and outcomes. Chest. (1996) 110:249-55. doi: 10.1378/chest.110.1.249

94. Abuzinadah AR, AlShareef AA, AlKutbi A, Bamaga AK, Alshehri A, Algahtani $\mathrm{H}$, et al. Amyotrophic lateral sclerosis care in Saudi Arabia: A survey of providers' perceptions. Brain Behav. (2020) 10:e01795. doi: 10.1002/brb3.1795

95. Andersen PM, Kuzma-Kozakiewicz M, Keller J, Aho-Oezhan HEA, Ciecwierska K, Szejko N, et al. Therapeutic decisions in ALS patients: crosscultural differences and clinical implications. J Neurol. (2018) 265:16006. doi: 10.1007/s00415-018-8861-4

96. BuŽgová R, Kozáková R, Juríčková L. The unmet needs of family members of patients with progressive neurological disease in the Czech Republic. PLoS ONE. (2019) 14:e0214395. doi: 10.1371/journal.pone.0214395

97. Cipolletta S, Reggiani M. End-of-life care after the legal introduction of advance directives: A qualitative study involving healthcare professionals and family caregivers of patients with amyotrophic lateral sclerosis. Palliat Med. (2021) 35:209-18. doi: 10.1177/0269216320967280

98. Gofton TE, Chum M, Schulz V, Gofton BT, Sarpal A, Watling C. Challenges facing palliative neurology practice: A qualitative analysis. J Neurol Sci. (2018) 385:225-31. doi: 10.1016/j.jns.2017.12.008

99. Lee JE, Goo A, Shin DW, Yoo JH. Korean medical professionals' attitudes and experiences on advance care planning for noncancerous disease. Ann Geriatr Med Res. (2019) 23:63-70. doi: 10.4235/agmr.19. 0010

100. Thurn T, Borasio GD, Chiò A, Galvin M, McDermott CJ, Mora G, et al. Physicians' attitudes toward end-of-life decisions in amyotrophic lateral sclerosis. Amyotroph Lateral Scler Front Degener. (2019) 20:7481. doi: 10.1080/21678421.2018.1536154

101. Wales J, Isenberg SR, Wegier P, Shapiro J, Cellarius V, Buchman S, et al. Providing medical assistance in dying within a home palliative care program in Toronto, Canada: an observational study of the first year of experience. $J$ Palliat Med. (2018) 21:1573-9. doi: 10.1089/jpm.2018.0175

102. Winther D, Lorenzen CK, Dreyer P. Everyday life experiences of close relatives of people with amyotrophic lateral sclerosis receiving home mechanical ventilation-A qualitative study. J Clin Nurs. (2020) 29:2306-16. doi: 10.1111/jocn.15239

103. McVeigh C, Donaghy C, Mc Laughlin B, Dick A, Kaur K, Mc Conville J, et al. Palliative care for patients with motor neurone disease and their bereaved carers: a qualitative study. BMC Palliat Care. (2019) 18. doi: 10.1186/s12904-019-0423-8

104. Wiebe E, Shaw J, Green S, Trouton K, Kelly M. Reasons for requesting medical assistance in dying. Can Fam Physician. (2018) 64:674-9.

105. Funke A, Spittel S, Grehl T, Grosskreutz J, Kettemann D, Petri S, et al. Provision of assistive technology devices among people with ALS in Germany: a platform-case management approach. Amyotroph Lateral Scler Front Degener. (2018) 19:342-50. doi: 10.1080/21678421.2018.1431786

106. Wasner M, Klier H, Borasio GD. The use of alternative medicine by patients with amyotrophic lateral sclerosis. J Neurol Sci. (2001) 191:1514. doi: 10.1016/S0022-510X(01)00615-3

107. Lerum SV, Solbrække KN, Holmøy T, Frich JC. Unstable terminality: negotiating the meaning of chronicity and terminality in motor neurone disease. Sociol Health Illn. (2015) 37:81-96. doi: 10.1111/1467-9566. 12182

108. Preston H, Fineberg IC, Callagher P, Mitchell DJ. The preferred priorities for care document in motor neurone disease: views of bereaved relatives and carers. Palliat Med. (2012) 26:132-8. doi: 10.1177/0269216311399664

109. Ang K, Umapathi T, Tong J, Ng J, Tseng LJ, Woo IMH. Healthcare needs of patients with amyotrophic lateral sclerosis (ALS) in Singapore: A patientcentered qualitative study from multiple perspectives. J Palliat Care. (2015) 31:150-7. doi: 10.1177/082585971503100304

110. Cheung K-C, Lau VW-K, Un K-C, Wong M-S, Chan K-Y. Advance care planning for patients with advanced neurology diseases. Ann Palliat Med. (2018) 7:34954-34354. doi: 10.21037/apm.2017.09.10

111. Craig A, Dzeng E. How Should physicians care for dying patients with amyotrophic lateral sclerosis? AMA J Ethics. (2018) 20:6908. doi: 10.1001/amajethics.2018.690

112. Helleman J, Eenennaam RV, Kruitwagen ET, Kruithof WJ, Slappendel MJ, Berg LHVD. et al. Telehealth as part of specialized ALS care: feasibility and user experiences with "ALS home-monitoring and coaching". Amyotroph Lateral Scler Front Degener. (2020) 21:183-92. doi: 10.1080/21678421.2020.1718712

113. Ohnsorge K, Rehmann-Sutter C, Streeck N, Gudat H. Wishes to die at the end of life and subjective experience of four different typical dying trajectories. A qualitative interview study. PLOS ONE. (2019) 14:e0210784. doi: 10.1371/journal.pone.0210784

114. Tobin K, Maguire S, Corr B, Normand C, Hardiman O, Galvin M. Discrete choice experiment for eliciting preference for health services for patients with ALS and their informal caregivers. BMC Health Serv Res. (2021) 21:213. doi: 10.1186/s12913-021-06191-Z

115. Almack K, Cox K, Moghaddam N, Pollock K, Seymour J. After you: conversations between patients and healthcare professionals in planning for end of life care. BMC Palliat Care. (2012) 11:15. doi: 10.1186/1472-684X-11-15

116. Langbroek PM, van den Bos K, Simon Thomas M, Milo JM, van Rossum WM. Methodology of Legal Research: Challenges and Opportunities. Utrecht Law Rev. (2017) 13:1-8. doi: 10.18352/ulr.411

117. Bolmsjö I. Existential issues in palliative care: interviews of patients with amyotrophic lateral sclerosis. J Palliat Med. (2001) 4:499-505. doi: 10.1089/109662101753381647

118. Rabkin J, Ogino M, Goetz R, McElhiney M, Hupf J, Heitzman $\mathrm{D}$, et al. Japanese and American ALS patient preferences regarding TIV (tracheostomy with invasive ventilation): a crossnational survey. Amyotroph Lateral Scler Front Degener. (2014) 15:185-91. doi: 10.3109/21678421.2014.896928

119. Kuzma-Kozakiewicz M, Andersen PM, Ciecwierska K, Vázquez C, Helczyk $\mathrm{O}$, Loose $\mathrm{M}$, et al. An observational study on quality of life and preferences to sustain life in locked-in state. Neurology. (2019) 93:e938-45. doi: 10.1212/WNL.0000000000008064

120. Cheng HWB, Chan OMI, Chan CHR, Chan WH, Fung KS, Wong KY. End-of-life Characteristics and palliative care provision for patients with motor neuron disease. Am J Hosp Palliat Med. (2018) 35:84751. doi: $10.1177 / 1049909117735832$ 
121. Chhetri SK, Bradley BF, Callagher P, Addison-Jones R, Bennett W, Gardham J, et al. Choosing the place of death: Empowering motor neurone disease/amyotrophic lateral sclerosis patients in end-of-life care decision making. Palliat Med. (2015) 29:667-8. doi: 10.1177/02692163155 70412

122. Weber C, Fijalkowska B, Ciecwierska K, Lindblad A, Badura-Lotter G, Andersen PM, et al. Existential decision-making in a fatal progressive disease: how much do legal and medical frameworks matter? BMC Palliat Care. (2017) 16:80. doi: 10.1186/s12904-017-0252-6

123. Astrow AB, Sood JR, Nolan MT, Terry PB, Clawson L, Kub J, et al. Decisionmaking in patients with advanced cancer compared with amyotrophic lateral sclerosis. J Med Ethics. (2008) 34:664-8. doi: 10.1136/jme.2007.022731

124. Rabkin J, Ogino M, Goetz R, McElhiney M, Marziliano A, Imai T, et al. Tracheostomy with invasive ventilation for ALS patients: neurologists' roles in the US and Japan. Amyotroph Lateral Scler Front Degener. (2013) 14:11623. doi: $10.3109 / 17482968.2012 .726226$

125. Ruffell TO, Martin NH, Janssen A, Wijesekera L, Knights C, Burman $\mathrm{R}$, et al. Healthcare professionals' views on the provision of gastrostomy and noninvasive ventilation to amyotrophic lateral sclerosis patients in England, Wales, and Northern Ireland. J Palliat Care. (2013) 29:22531. doi: $10.1177 / 082585971302900404$

126. Russell JA, Williams MA, Drogan O. Sedation for the imminently dying: survey results from the AAN Ethics Section. Neurology. (2010) 74:13039. doi: 10.1212/WNL.0b013e3181d9edcb

127. Baxter SK, Baird WO, Thompson S, Bianchi SM, Walters SJ, Lee E, et al. The use of non-invasive ventilation at end of life in patients with motor neurone disease: a qualitative exploration of family carer and health professional experiences. Palliat Med. (2013) 27:516-23. doi: 10.1177/0269216313478449

128. Christodoulou G, Goetz R, Ogino M, Mitsumoto H, Rabkin J. Opinions of Japanese and American ALS caregivers regarding tracheostomy with invasive ventilation (TIV). Amyotroph Lateral Scler Front Degener. (2015) 17:47-54. doi: 10.3109/21678421.2015.1069850

129. Ho GWK, Skaggs L, Yenokyan G, Kellogg A, Johnson JA, Lee MC. H, et al. Patient and caregiver characteristics related to completion of advance directives in terminally ill patients. Palliat Support Care. (2017) 15:129. doi: $10.1017 /$ S147895151600016X

130. Lerum SV, Solbraekke KN, Frich JC. Healthcare professionals' accounts of challenges in managing motor neurone disease in primary healthcare: a qualitative study. Health Soc Care Community. (2017) 25:135563. doi: $10.1111 / \mathrm{hsc} .12432$

131. Levi BH, Simmons Z, Hanna C, Brothers A, Lehman E, Farace E, et al. Advance care planning for patients with amyotrophic lateral sclerosis. Amyotroph Lateral Scler Front Degener. (2017) 18:388-96. doi: 10.1080/21678421.2017.1285317

132. Burchardi N, Rauprich O, Hecht M, Beck M, Vollmann J. Discussing living wills. A qualitative study of a German sample of neurologists and ALS patients. J Neurol Sci. (2005) 237:67-74. doi: 10.1016/j.jns.2005.05.013

133. Chiò A, Silani V, Italian ALS. Study Group. Amyotrophic lateral sclerosis care in Italy: a nationwide study in neurological centers. J Neurol Sci. (2001) 191:145-50. doi: 10.1016/S0022-510X(01)00622-0

134. Clabburn O, Knighting K, Jack BA, O'Brien MR. The use of digital legacies with people affected by motor neurone disease for continuing bonds: An interpretative phenomenological analysis study. Palliat Med. (2019) 33:81222. doi: $10.1177 / 0269216319845805$

135. Costa TD de C, Alves AMP de M, Costa E de O, Acioly CMC, Batista PS de S. Palliative care to patients with amyotrophic lateral sclerosis: experiences of physiotherapists in a hospital setting / Cuidados paliativos ao paciente com esclerose lateral amiotrófica: vivência de fisioterapeutas no âmbito hospitalar. RPCFO. (2020) 12:1334-40. doi: 10.9789/2175-5361.rpcfo.v12.9465

136. Maetens A, Deliens L, De Bleecker J, Caraceni A, De Ridder M, Beernaert K, et al. Healthcare utilization at the end of life in people dying from amyotrophic lateral sclerosis: A retrospective cohort study using linked administrative data. J Neurol Sci. (2019) 406:116444. doi: 10.1016/j.jns.2019.116444

137. Spataro R, La Bella V. The capacity to consent to treatment in amyotrophic lateral sclerosis: a preliminary report. J Neurol. (2021) 268:21926. doi: 10.1007/s00415-020-10136-7
138. Dreyer PS, Felding M, Klitnæs CS, Lorenzen CK. Withdrawal of invasive home mechanical ventilation in patients with advanced amyotrophic lateral sclerosis: ten years of Danish experience. J Palliat Med. (2012) 15:2059. doi: 10.1089/jpm.2011.0133

139. Borasio GD, Shaw PJ, Hardiman O, Ludolph AC, Sales Luis ML, Silani V, et al. Study Group. Standards of palliative care for patients with amyotrophic lateral sclerosis: results of a European survey. Amyotroph Lateral Scler Mot Neuron Disord Off Publ World Fed Neurol Res Group Mot Neuron Dis. (2001) 2:159-64. doi: 10.1080/146608201753275517

140. Fanos JH, Gelinas DF, Miller RG. "You have shown me my end": attitudes toward presymptomatic testing for familial amyotrophic lateral sclerosis. Am J Med Genet A. (2004) 129A:248-253. doi: 10.1002/ajmg.a.30178

141. Veldink JH, Wokke JHJ, van der Wal G, Vianney de. Jong JMB, van den Berg LH. Euthanasia and physician-assisted suicide among patients with amyotrophic lateral sclerosis in the Netherlands. N Engl J Med. (2002) 346:1638-44. doi: 10.1056/NEJMsa012739

142. Vianello A, Arcaro G, Palmieri A, Ermani M, Braccioni F, Gallan F, et al. Survival and quality of life after tracheostomy for acute respiratory failure in patients with amyotrophic lateral sclerosis. J Crit Care. (2011) 26:329.e714. doi: $10.1016 /$ j.jcrc.2010.06.003

143. Vitale A, Genge A. Codman Award 2006: the experience of hope in ALS patients. Axone Dartm NS. (2007) 28:27-35.

144. Bentley B, O'Connor M, Breen LJ, Kane R. Feasibility, acceptability and potential effectiveness of dignity therapy for family carers of people with motor neurone disease. BMC Palliat Care. (2014) 13:12. doi: $10.1186 / 1472-684 \mathrm{X}-13-12$

145. Esposito SJ, Mitsumoto H, Shanks M. Use of palatal lift and palatal augmentation prostheses to improve dysarthria in patients with amyotrophic lateral sclerosis: a case series. J Prosthet Dent. (2000) 83:90-8. doi: 10.1016/S0022-3913(00)70093-X

146. Aoun SM, Chochinov HM, Kristjanson LJ. Dignity therapy for people with motor neuron disease and their family caregivers: a feasibility study. J Palliat Med. (2015) 18:31-7. doi: 10.1089/jpm.2014.0213

147. Hack TF, McClement SE, Chochinov HM, Dufault B, Johnston W, Enns MW, et al. Assessing symptoms, concerns, and quality of life in noncancer patients at end of life: how concordant are patients and family proxy members? J Pain Symptom Manage. (2018) 56:760-6. doi: 10.1016/j.jpainsymman.2018.07.019

148. Sulmasy DP, Terry PB, Weisman CS, Miller DJ, Stallings RY, Vettese MA, et al. The accuracy of substituted judgments in patients with terminal diagnoses. Ann Intern Med. (1998) 128:621-9. doi: 10.7326/0003-4819-128-8-199804150-00002

149. Abrahao A, Downar J, Pinto H, Dupré N, Izenberg A, Kingston W, et al. Physician-assisted death: A Canada-wide survey of ALS health care providers. Neurology. (2016) 87:115260. doi: 10.1212/WNL.0000000000002786

150. Stutzki R, Weber M, Reiter-Theil S, Simmen U, Borasio GD, Jox RJ. Attitudes toward hastened death in ALS: A prospective study of patients and family caregivers. Amyotroph Lateral Scler Front Degener. (2014) 15:6876. doi: $10.3109 / 21678421.2013 .837928$

151. Son D, Shimizu I, Ishikawa H, Aomatsu M, Leppink J. Communication skills training and the conceptual structure of empathy among medical students. Perspect Med Educ. (2018) 7:264-71. doi: 10.1007/s40037-018-0431-z

152. Fliedner M, Halfens RJG, King CR, Eychmueller S, Lohrmann C, Schols JMGA. Roles and responsibilities of nurses in advance care planning in palliative care in the acute care setting: a scoping review. J Hosp Palliat Nurs. (2021) 23:59-68. doi: 10.1097/NJH.00000000000 00715

153. Moore PM, Rivera S, Bravo-Soto GA, Olivares C, Lawrie TA. Communication skills training for healthcare professionals working with people who have cancer. Cochrane Database Syst Rev. (2018) 2018. doi: $10.1002 / 14651858$.CD003751.pub4

154. Tanzi S, De Panfilis L, Costantini M, Artioli G, Alquati S, Di Leo S. Development and preliminary evaluation of a communication skills training programme for hospital physicians by a specialized palliative care service: the 'Teach to Talk' programme. BMC Med Educ. (2020) 20:363. doi: 10.1186/s12909-020-02275-2

155. Chang H-T, Lin M-H, Chen C-K, Hwang S-J, Hwang I-H, Chen Y-C. Hospice palliative care article publications: An analysis of the Web of 
Science database from 1993 to 2013. J Chin Med Assoc. (2016) 79:2933. doi: 10.1016/j.jcma.2015.05.012

156. Damarell RA, Tieman JJ. Searching PubMed for a broad subject area: how effective are palliative care clinicians in finding the evidence in their field? Health Inf Libr J. (2016) 33:49-60. doi: 10.1111/hir.12120

157. Tieman J, Sladek R, Currow D. Multiple sources: mapping the literature of palliative care. Palliat Med. (2009) 23:42531. doi: $10.1177 / 0269216309102727$

158. Achille MA, Ogloff JRP. Attitudes toward and desire for assisted suicide among persons with amyotrophic lateral sclerosis. OMEGA - J Death Dying. (2004) 48:1-21. doi: 10.2190/G5TA-9KV0-MT3G-RWM0

159. Lulé D, Nonnenmacher S, Sorg S, Heimrath J, Hautzinger M, Meyer T, et al. Live and let die: existential decision processes in a fatal disease. J Neurol. (2014) 261:518-25. doi: 10.1007/s00415-013-7229-Z

160. Kanniyakonil S. New developments in India concerning the policy of passive euthanasia. Dev World Bioeth. (2018) 18:190-7. doi: 10.1111/dewb. 12187

161. Bulmer M, Bahnke JR, Lewis GJ. Predicting moral sentiment toward physician-assisted suicide: The role of religion, conservatism, authoritarianism, and Big Five personality. Personal Individ Differ. (2017) 105:244-51. doi: 10.1016/j.paid.2016.09.034

162. Gourie-Devi M, Gupta R, Sharma V, Pardasani V. Maheshwari S. An insight into death wish among patients with amyotrophic lateral sclerosis in India using "Wish-to-Die Questionnaire". Neurol India. (2017) 65:46-51. doi: 10.4103/0028-3886.198177

163. Archer W, Latif A, Faull C. Communicating with palliative care patients nearing the end of life, their families and carers. Pharm J. (2017) 298. doi: 10.1211/PJ.2017.20202154

164. Brighton LJ, Bristowe K. Communication in palliative care: talking about the end of life, before the end of life. Postgrad Med J. (2016) 92:46670. doi: 10.1136/postgradmedj-2015-133368

165. Abdulla S, Vielhaber S, Machts J, Heinze H-J, Dengler R, Petri S. Information needs and information-seeking preferences of ALS patients and their carers. Amyotroph Lateral Scler Front Degener. (2014) 15:50512. doi: $10.3109 / 21678421.2014 .932385$

166. Chen Z, Turner MR. The internet for self-diagnosis and prognostication in ALS. Amyotroph Lateral Scler. (2010) 11:565-7. doi: 10.3109/17482968.2010.513054

167. Moccia M, Brigo F, Tedeschi G, Bonavita S, Lavorgna L. Neurology and the internet: a review. Neurol Sci. (2018) 39:981-7. doi: 10.1007/s10072-018-3339-9

168. Oh J, Kim JA. Information-seeking behavior and information needs in patients with amyotrophic lateral sclerosis: analyzing an online patient community. CIN Comput Inform Nurs. (2017) 35:345-51. doi: 10.1097/CIN.00000000000 00333

169. van Berkel JJ, Lambooij MS, Hegger I. Empowerment of patients in online discussions about medicine use. BMC Med Inform Decis Mak. (2015) 15:24. doi: 10.1186/s12911-0150146-6

170. Wicks P. “They embrace you virtually': The internet as a tool for social support for people with ALS," in Amyotrophic Lateral Sclerosis: Understanding and Optimizing Quality of Life and Psychological WellBeing. Oxford University Press. p. 185-97. Available online at: http:// oxfordmedicine.com/view/10.1093/med/9780198757726.001.0001/med9780198757726-chapter-11 (accessed April 9, 2019).

171. Oh J, Kim JA. Supportive care needs of patients with amyotrophic lateral sclerosis/motor neuron disease and their caregivers: A scoping review. J Clin Nurs. (2017) 26:4129-52. doi: 10.1111/jocn.13945
172. Pols J, Limburg S, A. Matter of Taste? Quality of Life in Day-to-Day Living with ALS and a Feeding Tube. Cult Med Psychiatry. (2016) 40:36182. doi: 10.1007/s11013-015-9479-y

173. Niedermeyer S, Murn M, Choi PJ. Respiratory failure in amyotrophic lateral sclerosis. Chest. (2019) 155:401-8. doi: 10.1016/j.chest.2018.06.035

174. Berkey FJ, Wiedemer JP, Vithalani ND. Delivering bad or life-altering news. Am Fam Physician. (2018) 98:99-104.

175. Visser M, Deliens L, Houttekier D. Physician-related barriers to communication and patient- and family-centered decision-making toward the end of life in intensive care: a systematic review. Crit Care. (2014) 18:1-19. doi: 10.1186/s13054-014-0604-z

176. Beukelman D, Fager S, Nordness A. communication support for people with ALS. Neurol Res Int. (2011) 2011. doi: 10.1155/2011/714693

177. Tomik B, Professor RJG. Dysarthria in amyotrophic lateral sclerosis: A review. Amyotroph Lateral Scler. (2010) 11:415. doi: $10.3109 / 17482960802379004$

178. Caulfield T, Ogbogu U. The commercialization of university-based research: Balancing risks and benefits. BMC Med Ethics. (2015) 16:70. doi: 10.1186/s12910-015-0064-2

179. Fabbri A, Lai A, Grundy Q, Bero LA. The Influence of Industry Sponsorship on the Research Agenda: A Scoping Review. Am J Public Health. (2018) 108:e9-e16. doi: 10.2105/AJPH.2018.304677

180. ALS Canada: Projects funded. ALS Soc Can. Available online at: https://www. als.ca/research/als-canada-research-program/projects-funded/ (accessed September 12, 2019).

181. MNDA: Research we fund. MND Assoc. (2019). Available online at: https://www.mndassociation.org/research/our-research/research-we-fund/ (accessed September 12, 2019).

182. The ALS Association: Research we fund. ALS Assoc. (2019). Available online at: http://www.alsa.org/research/research-we-fund/ (accessed September 12, 2019).

183. Bahus MK, Steen PA, Førde R. Law, ethics and clinical judgment in endof-life decisions-How do Norwegian doctors think? Resuscitation. (2012) 83:1369-73. doi: 10.1016/j.resuscitation.2012.04.008

184. Gross RA, Johnston KC. Levels of evidence: Taking Neurology(R) to the next level. Neurology. (2009) 72:8-10. doi: 10.1212/01.wnl.0000342200.58823.6a

185. McConville M, Chui WH. "Introduction and Overview," In: McConville M, Chui WH, editors. Research Methods for Law. Edinburgh University Press. p. 1-17. Available online at: https://www.jstor.org/stable/10.3366/j.ctt1g0b16n. 6 (accessed June 13, 2019).

Conflict of Interest: The authors declare that the research was conducted in the absence of any commercial or financial relationships that could be construed as a potential conflict of interest.

Publisher's Note: All claims expressed in this article are solely those of the authors and do not necessarily represent those of their affiliated organizations, or those of the publisher, the editors and the reviewers. Any product that may be evaluated in this article, or claim that may be made by its manufacturer, is not guaranteed or endorsed by the publisher.

Copyright (c) 2021 Genuis, Luth, Campbell, Bubela and Johnston. This is an openaccess article distributed under the terms of the Creative Commons Attribution License (CC BY). The use, distribution or reproduction in other forums is permitted, provided the original author(s) and the copyright owner(s) are credited and that the original publication in this journal is cited, in accordance with accepted academic practice. No use, distribution or reproduction is permitted which does not comply with these terms. 